\title{
Evaluation of The Effectiveness of The Standard Traditional Korean Medicine-Based Health Promotion Program For Disadvantaged Children In South Korea
}

\author{
Eunhye Hyun \\ Pusan National University \\ Jiseon Ryu \\ Kijang-Yeonse nursing hospital \\ Kibong Kim \\ Pusan National University \\ Sangjae Lee \\ Pusan National University \\ Seungtae Kim \\ Pusan National University \\ Byungmook Lim ( $\square$ limb@pusan.ac.kr) \\ Pusan National University
}

\section{Research Article}

Keywords: traditional Korean Medicine, disadvantaged children, health promotion, quasi-experimental design, difference-in-differences model

Posted Date: January 24th, 2022

DOI: https://doi.org/10.21203/rs.3.rs-1207272/v1

License: 두 (i) This work is licensed under a Creative Commons Attribution 4.0 International License. Read Full License 


\section{Abstract}

Background: Traditional Korean Medicine (TKM) is highly integrated with the modern health care system of South Korea and is actively used in the public health field. Since 2014, the Ministry of Health and Welfare of South Korea has supported the development of standard models for TKM-based health promotion programs. This study aimed to report and evaluate a standard TKM-based health promotion program for the health of disadvantaged children.

Methods: The program was developed based on previous studies, on-site surveys, and expert advice. It was applied to children in the intervention group for 12 weeks, but not to children in the wait-list control group. The program's effectiveness indicators-the number of outpatient visits, absence, late or early leave, and infectious symptoms-were compared between groups. For statistical analysis, difference-in-differences model with a zeroinflated negative binomial regression model was used.

Results: At baseline, there were 156 children in the intervention group and 153 children in the wait-list control group, among which 155 and 147 children, respectively, were included in the analysis. The number of outpatient visits was significantly lower (by $65 \%)$ in the intervention group than in the wait-list control group $(p=0.03)$. The number of absences, lateness/early leaves, and infectious symptoms were $51 \%, 47 \%$, and $14 \%$ lower, respectively, in the intervention group than in the wait-list control group, but the difference was not statistically significant.

Conclusions: A standard TKM-based health promotion program has the potential to improve the health of disadvantaged children. In the future, studies with long-term intervention and large-scale subjects are needed to enhance the applicability of these programs in communities.

\section{Background}

It is well known that individuals in unfavorable environments are more susceptible to negative health outcomes [1]. In particular, if a child has grown up in a structurally or economically disadvantageous parenting environment, the child is likely to have a lower socioeconomic status and poorer health condition in adulthood [2-4]. Therefore, a proactive approach to children's health issues is required at the social level [5].

In South Korea, not only conventional medicine but also traditional Korean medicine (TKM) is used to provide social support for children's health. TKM has been highly integrated into the nation's health care system, and many TKM procedures provided at hospitals or clinics have been covered by the National Health Insurance since 1987 [6]. The usage of TKM in the public health field began in earnest during the early 2000s, when the Ministry of Health and Welfare encouraged public health centers of communities to implement TKM-based health promotion programs reflecting the healthrelated needs of community residents [7]. As part of these, various TKM-based health promotion programs were conducted, such as Qi-gong exercise classes, stroke prevention classes, Sa-sang constitution health classes, pre- and post-natal health classes, child-caring classes, smoking cessation classes, and home visit care services $[7,8]$. This raised the interest of community residents in health promotion and yielded high satisfaction and positive possibilities [7-11].

However, as the programs were introduced at each public health center autonomously, several problems appeared. Owing to the differences in budget level and human resources in each community, the relevant departments or personnel were either excessively deployed or insufficient [12, 13]. In particular, the lack of resources caused the quality of projects to stagnate, which in turn reduced participation of community residents. This made it difficult to recruit participants necessary for the performance evaluation of the program; therefore, there was a limit to the systematic performance evaluation of the program [7, 12]. Also, more than half of the public health TKM doctors who worked at the public health centers at the time critically pointed out that there was no systematic manual not only for the application of the program but also for the evaluation of its performance, which led to poor participation of key staff [14].

To address the above problems, the Ministry of Health and Welfare, with its affiliate organization-the Korea Health Promotion Institution, supported the development of standard and systemic TKM-based health promotion programs since 2014 [8]. Since then, a total of eight standard programs for infants, adolescents, pregnant, adults, elderly, and disadvantaged groups have been developed and used in public health centers nationwide [8]. This study aimed to report and evaluate a standard government supported TKM-based health promotion program for the health of disadvantaged children.

\section{Methods}

\subsection{Study design}

A quasi-experimental, non-equivalent, prospective study involving children from a Community Children's Center (CCC) in South Korea was designed to evaluate the effectiveness of the standard TKM-based health promotion program for disadvantaged children.

\subsection{Participants and data}

The CCC is a welfare facility for children from socially disadvantaged families that provides comprehensive childcare services ranging from care, education, and entertainment [15]. Since its enactment in 2004, more than 100,000 children are being taken care of every day in more than 4,000 
CCCs across South Korea [16]. However, most of the services provided in CCCs are limited to care and education, leaving little support for essential health promotion services required for children [17].

In this study, 16 CCCs located in Busan and Yangsan, South Korea that agreed to participate in the study were divided into two groups of eight CCCs based on center's geographical location and size. Children from eight CCCs were included in the intervention group and underwent a 12-week TKMbased health promotion program. Children from the other eight CCCs were included in the wait-list control group (control group) and did not undergo the program. Instead, after the waiting period ended and the analysis of the results was complete, the children in the control group were provided with the same program.

The data for the analysis of the effectiveness of the program were collected through pre- and post-surveys on legal representatives (caregivers) of children. The pre-survey questionnaire consisted of children's demographic characteristics, medical use, and health status. The post-survey questionnaire excluded only demographic questions from the pre-survey. The same two questionnaires were administered to the intervention and control groups. The results of the program applied to the control group after the waiting period were not included in the effectiveness analysis.

\subsection{Intervention: standard TKM-based health promotion program}

In this study, the standard TKM-based health promotion program was developed in accordance with a previous guideline [18] to reflect health-related issues and the needs of disadvantaged children in primary care settings. In the first phase, researchers visited the participating CCCs to conduct indepth interviews and surveys on CCC teachers and children and identify major health issues and related environmental status. In the second phase, the program was drafted by prioritizing health issues and needs. In the third phase, the draft was revised based on expert advice, and the final program was developed.

Staff participating in the program included CCC teachers, children and their caregivers, and TKM doctors. A total of eight TKM doctors in private clinics participated voluntarily, and each TKM doctor was assigned to each intervention CCC as an attending physician. They provided comprehensive health promotion services based on TKM throughout the 12-week program. In particular, for 'Medical examination and counselling' and 'Education', TKM doctors visited the CCCs four times within the 12-week program. The standard TKM-based health promotion program consisted of four parts as follows.

\section{Part 1. Medical examination and counselling}

Medical examination and counselling were conducted in cooperation with CCC teachers, children's caregivers, and TKM doctors. Basic medical examination data were collected by CCC teachers and children's caregivers. The CCC teachers compiled information collected through 'Daily management (Part 3)' and 'Health monitoring (Part 4)'. The children's caregivers completed the Weak Children Questionnaire [19], which is a checklist of children's respiratory and digestive symptoms. The TKM doctors compiled the reported information, comprehensively examined the children, and provided counselling, including advice or emotional support.

\section{Part 2. Education}

The TKM doctor visited the CCC to provide regular education for children and CCC teachers. The contents of regular education consisted of hygiene management, healthy habits in the summer season, growth promotion gymnastics, and allergic disease prevention. In addition, video materials were provided so that children could take care of their health both at the CCC and at home. The CCC teacher ensured that the children completed their regular education and assisted them in smoothly performing healthcare activities within the CCC.

\section{Part 3. Daily management}

For children with early respiratory, digestive, ophthalmological, otolaryngological, and dermatological symptoms, the CCC teacher treated them with in-house medicines with the consent of the children's caregivers and consultation with TKM doctor. The in-house medicines included extracts, syruptype fever reducers, and ointments from herbal medicine.

\section{Part 4. Health monitoring}

The CCC teacher checked the attendance status of the children to the CCC and whether children had abnormal physical conditions that required medical examination or treatment. The CCC teacher also assisted the children in filling out their health notebooks. Children self-reported data on health management activities by filling out data on their health status and how they performed the health care activities in notebooks, and the information from the notebooks was also used as a reference by TKM doctors during medical examinations and counselling (Part 1). The TKM doctor monitored the children's health online or over the phone and provided constant advice.

\subsection{Variable}

To evaluate the effectiveness of the program, four outcome variables that could reflect the medical use and health status of children were selected as follows: the number of \outpatient visits, \absence, $\nabla$ lateness/early leaves, and \infectious symptoms. Frequency measurements were limited to respiratory, digestive, ophthalmological, otolaryngological, and dermatological diseases, which have a large degree of incidence and clinical 
significance in children [20-22]. The number of outpatient visits, absence, and lateness/early leaves was limited to cases within the last 1 month, and the number of infectious symptoms was limited to cases within the last 2 weeks [23].

Control variables are upstream factors [24] that are expected to affect children's medical use and health conditions in addition to the intervention program $[17,25,26]$. Eight control variables were set in dummy format, including sex, age, having sibling(s), main caregiver, family type, household income, maternal education level, and past medical history. Control variable data is described without being mapped to any specific table column. The inter-connection effects between the control variables were minimized using pie coefficients.

\subsection{Statistical Analysis}

Although there were some non-response items in the resulting data, the bias was assumed to be negligible because the proportion of non-responses was $<5 \%$ of the total number of responses [27]. An intention-to-treat analysis [28] was performed using the R studio version 1.3 .1056 ( $R$ studio, Boston), and a significance level of 0.05 with a two-tailed confidence interval of $95 \%$ was set. Statistical analyses were performed as follows:

First, a homogeneity test of the sociodemographic characteristics of the children involved in the study using the chi-square and Fisher-exact test.

Second, the main analysis that evaluated the effectiveness of the program using the Difference-in-Differences (DID) model with regression analysis [29]. The zero-inflated negative binomial (ZINB) regression model was fitted on the assumption that outcome variables were over-dispersed and zeroinflated $[30,31]$. The estimates from the DID model with ZINB regression analysis are presented as an Incident Rate Ratio (IRR), the exponentially multiplied value of the regression coefficient, $e^{\text {regressioncoefficient. }}$

$$
y_{i}=\alpha+\beta_{1} \text { (group*time) }+\beta_{2} \text { group }+\beta_{3} \text { time }+\beta_{4} X_{j}+\epsilon
$$

$y_{i}$ : Outcome variables (i=Outpatient visit, Absence, Lateness / early leave, Infectious symptom)

$\alpha$ : intercept

$\beta$ : regression coefficient

group: control group=0, intervention group $=1$

time: before the TKM program=0, after the TKM program=1

$X_{j}$ : control variables (j=sex, age, having sibling(s), main caregiver, family type, household income, maternal education level, and past medical history)

$\epsilon$ : error

$I R R=e^{\text {regressioncoefficient }}=e^{\beta}$

e : exponential

Third, the goodness-of-fit test was conducted to assess the suitability of the ZINB regression model to ensure the reliability of the analysis. The overdispersion assumption was evaluated using the likelihood-ratio test [32]. The zero-inflated assumption was evaluated using both the Vuong test [33] and Akaike's Information Criterion (AIC) [34], considering the limitations of the Vuong test [35].

\section{Results}

At baseline, 309 children (156 children in the intervention group and 153 children in the control group) were enrolled in the study. In total, 155 (99.4\%) children in the intervention group and 147 (96.1\%) children in the control group responded to the pre-survey. In the post-survey, 115 (73.7\%) children in the intervention group and 99 (64.7\%) children in the control group responded. Seven children (one child in the intervention group and six children in the control group) were excluded from the analysis because their questionnaires were not returned in the pre-survey, and there was no sociodemographic information available for analysis (Fig. 1).

\subsection{Homogeneity of children in the intervention group and control group}

The homogeneity of the participating children was also assessed. There was homogeneity between the intervention and control groups in the two surveys. In the pre-survey, there was no significant difference between the intervention and control groups for any of the characteristics. In the postsurvey, the intervention group had a significantly higher number of children with past medical history $(p=0.019)$ and present illness ( $p=0.043)$ than the control group (Table 1). 
Table 1

Homogeneity between the intervention group and control group

\begin{tabular}{|c|c|c|c|c|c|c|c|}
\hline & & \multicolumn{3}{|c|}{ Pre-survey (total n = 302) } & \multicolumn{3}{|c|}{ Post-survey (total $n=214$ ) } \\
\hline & & $\begin{array}{l}\text { Intervention group } \\
(\mathrm{n}=155)\end{array}$ & $\begin{array}{l}\text { Control group } \\
(n=147)\end{array}$ & $p$-value & $\begin{array}{l}\text { Intervention group } \\
(\mathrm{n}=115)\end{array}$ & $\begin{array}{l}\text { Control group } \\
(\mathrm{n}=99)\end{array}$ & p-value \\
\hline \multirow[t]{2}{*}{ Sex } & Male & $49.0 \%$ & $47.6 \%$ & \multirow[t]{2}{*}{0.806} & $52.2 \%$ & $47.5 \%$ & \multirow[t]{2}{*}{0.493} \\
\hline & Female & $51.0 \%$ & $52.4 \%$ & & $47.8 \%$ & $52.5 \%$ & \\
\hline \multirow[t]{3}{*}{ Age } & Mean (SD) & $10.4(1.6)$ & $10.5(1.7)$ & 0.761 & $10.4(1.7)$ & $10.4(1.7)$ & 0.881 \\
\hline & $>10$ years & $69.0 \%$ & $70.1 \%$ & \multirow[t]{2}{*}{0.845} & $66.1 \%$ & $66.7 \%$ & \multirow[t]{2}{*}{0.929} \\
\hline & $<10$ years & $31.0 \%$ & $29.9 \%$ & & $33.9 \%$ & $33.3 \%$ & \\
\hline \multirow[t]{2}{*}{ Having sibling(s) } & Yes & $85.5 \%$ & $87.4 \%$ & \multirow[t]{2}{*}{0.636} & $86.7 \%$ & $86.6 \%$ & \multirow[t]{2}{*}{0.978} \\
\hline & No & $14.5 \%$ & $12.6 \%$ & & $13.3 \%$ & $13.4 \%$ & \\
\hline \multirow[t]{2}{*}{ Main caregiver } & Mother & $74.7 \%$ & $72.8 \%$ & \multirow[t]{2}{*}{0.710} & $75.7 \%$ & $71.7 \%$ & \multirow[t]{2}{*}{0.513} \\
\hline & Others & $25.3 \%$ & $27.2 \%$ & & $24.3 \%$ & $29.3 \%$ & \\
\hline \multirow[t]{2}{*}{ Family type } & Two parents & $78.9 \%$ & $68.0 \%$ & \multirow[t]{2}{*}{0.032} & $80.5 \%$ & $70.7 \%$ & \multirow[t]{2}{*}{0.095} \\
\hline & Others & $21.1 \%$ & $32.0 \%$ & & $19.5 \%$ & $29.3 \%$ & \\
\hline \multirow[t]{2}{*}{ Insurance type } & $\mathrm{NHI}$ & $86.1 \%$ & $84.2 \%$ & \multirow[t]{2}{*}{0.647} & $84.0 \%$ & $85.1 \%$ & \multirow[t]{2}{*}{0.823} \\
\hline & Not NHI & $13.9 \%$ & $15.8 \%$ & & $16.0 \%$ & $14.9 \%$ & \\
\hline \multirow[t]{2}{*}{ Household income } & $>3000 \$$ & $32.0 \%$ & $32.6 \%$ & \multirow[t]{2}{*}{0.906} & $30.3 \%$ & $36.2 \%$ & \multirow[t]{2}{*}{0.373} \\
\hline & $<3000 \$$ & $68.0 \%$ & $67.4 \%$ & & $69.7 \%$ & $63.8 \%$ & \\
\hline \multirow[t]{3}{*}{ Paternal education level } & Over bachelor & $54.2 \%$ & $60.6 \%$ & \multirow[t]{3}{*}{0.296} & $51.6 \%$ & $55.6 \%$ & \multirow[t]{3}{*}{0.588} \\
\hline & Below & $45.8 \%$ & $39.4 \%$ & & $48.4 \%$ & $44.4 \%$ & \\
\hline & high school & & & & & & \\
\hline \multirow[t]{3}{*}{ Maternal education level } & Over bachelor & $54.7 \%$ & $50.4 \%$ & \multirow[t]{3}{*}{0.489} & $54.4 \%$ & $40.3 \%$ & \multirow[t]{3}{*}{0.061} \\
\hline & Below & $45.3 \%$ & $49.6 \%$ & & $45.6 \%$ & $59.7 \%$ & \\
\hline & high school & & & & & & \\
\hline Paternal occupation & Yes & $94.6 \%$ & $95.1 \%$ & 0.844 & $92.6 \%$ & $95.4 \%$ & 0.433 \\
\hline & No & $5.4 \%$ & $4.9 \%$ & & $7.4 \%$ & $4.6 \%$ & \\
\hline Maternal occupation & Yes & $68.6 \%$ & $69.1 \%$ & 0.932 & $71.2 \%$ & $69.4 \%$ & 0.794 \\
\hline & No & $31.4 \%$ & $30.9 \%$ & & $28.8 \%$ & $30.6 \%$ & \\
\hline Past medical history & Yes & $54.8 \%$ & $43.5 \%$ & 0.050 & $56.5 \%$ & $40.4 \%$ & $0.019 *$ \\
\hline & No & $45.2 \%$ & $56.5 \%$ & & $43.5 \%$ & $59.6 \%$ & \\
\hline Present illness & Yes & $25.8 \%$ & $19.0 \%$ & 0.160 & $31.3 \%$ & $19.2 \%$ & $0.043^{\star}$ \\
\hline & No & $74.2 \%$ & $81.0 \%$ & & $68.7 \%$ & $80.8 \%$ & \\
\hline * $p<0.05$, Statistically sign & ficant & & & & & & \\
\hline Abbreviations: SD, Standa & deviation; NHI, & ational Health Insu & nce & & & & \\
\hline
\end{tabular}

\subsection{Effectiveness of the program}

The number of outpatient visits in the intervention group was lower by $65 \%$ than that in the control group (IRR=0.35, $p=0.03)$. Further, the number of absences, lateness/early leave, and infectious symptoms decreased by $51 \%$ (IRR $=0.49), 47 \%$ (IRR=0.53), and $14 \%$ (IRR=0.86) in the intervention group compared to that in the control group, respectively, but the difference was not statistically significant (Table 2). 
Effectiveness of the program

\begin{tabular}{|c|c|c|c|c|c|c|c|c|c|c|c|c|c|c|c|c|}
\hline & \multicolumn{16}{|c|}{ Outcome variables } \\
\hline & \multicolumn{4}{|c|}{ Outpatient visit } & \multicolumn{4}{|c|}{ Absence } & \multicolumn{4}{|c|}{ Lateness / early leave } & \multicolumn{4}{|c|}{ Infectious symptom } \\
\hline & IRR & $\beta$ & SE & $\begin{array}{l}\mathrm{p}- \\
\text { value }\end{array}$ & IRR & $\beta$ & SE & $\begin{array}{l}\mathrm{p}- \\
\text { value }\end{array}$ & IRR & $\beta$ & SE & $\begin{array}{l}\mathrm{p}- \\
\text { value }\end{array}$ & IRR & $\beta$ & SE & $\begin{array}{l}\mathrm{p}- \\
\text { value }\end{array}$ \\
\hline \multicolumn{17}{|c|}{ Effectiveness of the program (group=1, time=1) } \\
\hline Group*time & 0.35 & -1.04 & 0.48 & 0.03 & 0.49 & -0.72 & 0.97 & 0.46 & 0.53 & -0.63 & 1.27 & 0.62 & 0.86 & -0.15 & 0.23 & 0.51 \\
\hline \multicolumn{17}{|c|}{ Control variables } \\
\hline $\begin{array}{l}\text { Sex } \\
\text { (ref. } \\
\text { female) }\end{array}$ & 0.87 & -0.14 & 0.24 & 0.57 & 0.33 & -1.11 & 0.48 & 0.02 & 0.13 & -2.06 & 1.02 & 0.04 & 1.00 & 0.00 & 0.12 & 0.99 \\
\hline $\begin{array}{l}\text { Age } \\
\text { (ref. >10 } \\
\text { years) }\end{array}$ & 0.55 & -0.59 & 0.26 & 0.02 & 1.57 & 0.45 & 0.56 & 0.42 & 0.07 & -2.69 & 0.95 & 0.00 & 0.94 & -0.06 & 0.13 & 0.64 \\
\hline $\begin{array}{l}\text { Having } \\
\text { sibling(s) } \\
\text { (ref. no) }\end{array}$ & 1.56 & 0.45 & 0.46 & 0.33 & 0.03 & -3.62 & 0.94 & 0.00 & 2.28 & 0.82 & 0.83 & 0.32 & 1.08 & 0.08 & 0.23 & 0.72 \\
\hline $\begin{array}{l}\text { Main } \\
\text { caregiver } \\
\text { (ref. } \\
\text { others) }\end{array}$ & 0.80 & -0.22 & 0.42 & 0.61 & 63.14 & 4.15 & 0.78 & 0.00 & 0.44 & -0.82 & 0.95 & 0.39 & 0.85 & -0.16 & 0.17 & 0.34 \\
\hline $\begin{array}{l}\text { Family } \\
\text { type } \\
\text { (ref. not } \\
\text { two } \\
\text { parents) }\end{array}$ & 1.59 & 0.46 & 0.36 & 0.20 & 3.21 & 1.16 & 0.61 & 0.06 & 0.32 & -1.15 & 0.89 & 0.20 & 0.84 & -0.17 & 0.16 & 0.28 \\
\hline $\begin{array}{l}\text { Household } \\
\text { income } \\
\text { (ref. } \\
<3000 \$ \text { ) }\end{array}$ & 0.79 & -0.24 & 0.28 & 0.39 & 4.21 & 1.44 & 0.54 & 0.01 & 6.67 & 1.90 & 0.81 & 0.02 & 1.08 & 0.08 & 0.14 & 0.56 \\
\hline $\begin{array}{l}\text { Maternal } \\
\text { education } \\
\text { level (ref. } \\
\text { below high } \\
\text { school) }\end{array}$ & 0.64 & -0.44 & 0.27 & 0.10 & 0.42 & -0.87 & 0.58 & 0.14 & 0.64 & -0.44 & 0.63 & 0.48 & 0.83 & -0.19 & 0.13 & 0.14 \\
\hline $\begin{array}{l}\text { Past } \\
\text { medical } \\
\text { history } \\
\text { (ref. no) }\end{array}$ & 2.06 & 0.72 & 0.25 & 0.00 & 0.79 & -0.24 & 0.51 & 0.64 & 20.73 & 3.03 & 0.81 & 0.00 & 1.74 & 0.56 & 0.13 & 0.00 \\
\hline Intercept & 0.68 & -0.38 & 0.70 & 0.58 & 0.41 & -0.90 & 0.74 & 0.23 & 1.55 & 0.44 & 1.97 & 0.82 & 1.35 & 0.30 & 0.34 & 0.37 \\
\hline * $p<0.05$, Sta & ically & significe & & & & & & & & & & & & & & \\
\hline
\end{tabular}

\subsection{Goodness of fit test}

As a result of the likelihood-ratio test, the likelihood of a negative-binomial model that reflects overdispersion assumptions was greater than that of a Poisson model that does not reflect overdispersion assumptions.

Based on negative binomial models, the suitability of the zero-inflated assumption was confirmed through the Vuong test. The ZINB model reflecting zero-inflated assumptions was significantly suitable for the number of outpatient visits and absences, but there was no significant difference in the number of lateness / early leaves and infectious symptoms. However, the additional analysis on AIC showed that it was more appropriate to reflect the zero-inflated assumptions in all four outcome variables (Table 3). 
Table 3

The result of Goodness of fit test

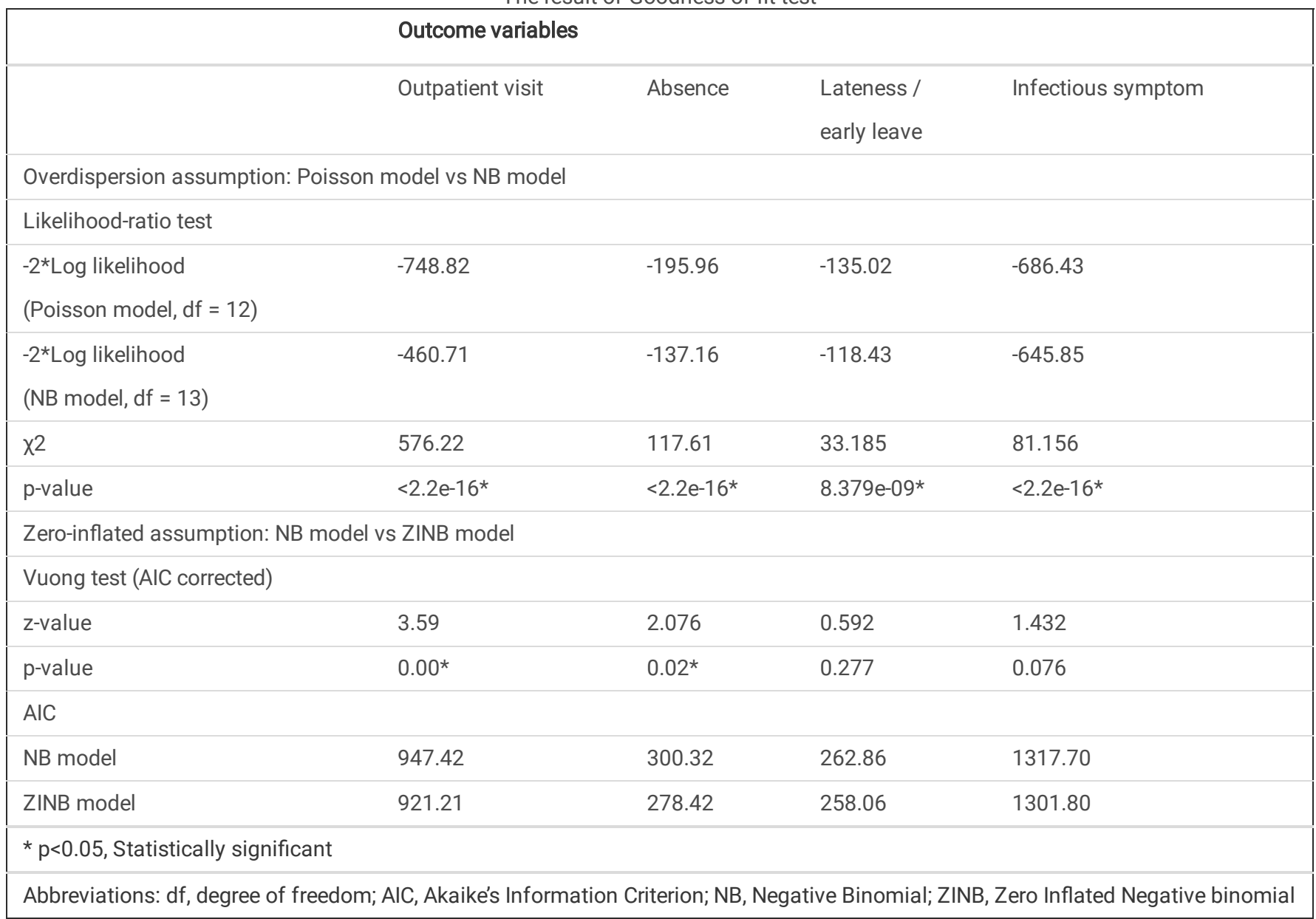

\section{Discussion}

In this study, we developed a TKM-based health promotion program as a strategy for disadvantaged children's health problems and evaluated its effectiveness based on the medical use and health conditions of children in CCCs. We found that the program significantly reduced the frequency of outpatient visits. The number of absences, lateness / early leave, and infectious symptoms tended to decrease, but not at a significant level.

The significant decrease in the number of outpatient visits is consistent with that reported in the study by Park et al [23], which was conducted to evaluate a TKM-based healthcare program for preventing infectious diseases in infants. This result showed that providing TKM doctor's visits to CCCs and necessary herbal medication over-the counter had the effect of replacing outpatient visits of disadvantaged children. If this program is extended to the local community at large, it would be more appropriate to use TKM doctors hired by local public health centers rather than those who run private clinics in consideration of cost-effectiveness.

Although the number of absences, lateness / early leave, and infectious symptoms in the intervention group tended to be lower than those in the control group, there was no significant difference between the groups. This result may be due to the following reasons. First, the intervention period of this study was from July to September, and in South Korea, August is the vacation period, so it is estimated that it was difficult to show a difference in attendance or lateness due to the small number of school days. In addition, in the case of infectious symptoms, it may have been difficult to detect a difference between the two groups because South Korea has a good sanitary environment with few digestive infections and respiratory infections generally occur frequently after October in South Korea's climate.

In analyzing the effectiveness, the individual effects of each part of the program were not analyzed separately. This complements the purpose of this study, which was to develop a comprehensive packaged service program rather than to prove the effects of a single intervention for health promotion.

The DIDs, used as the analysis model for this study, are popular in empirical research to estimate the causal effect of certain policy interventions or changes that cannot affect everybody at the same time and in the same way [29]. This model not only controls the unmeasured time-varying factors (trend effect) but also offsets the heterogeneity between the intervention and control groups through differences on the assumption that they are time invariant. However, even in DID, when setting up a control group, the propensity score matching method is used, or multiple control groups are included in consideration of internal validity. In this study, children's demographic information was collected as bivariate, which limited the accuracy 
of propensity score matching. In addition, it was difficult to set up multiple control groups because local communities and CCCs had different opinions and circumstances regarding participation.

To compensate for these problems, we conducted a homogeneity test and referred the results to program effects. Homogeneity tests showed some heterogeneity among participating children. However, it is unlikely that this would have overestimated the effectiveness of the program. According to the homogeneity test, there was no significant difference in demographic characteristics between the two groups in the pre-survey. In the post-survey, the proportion of children with past medical history and present illness was significantly higher in the intervention group than in the control group. This indicates that the effectiveness of the program was judiciously measured because the intervention group of the post-survey included more children with poor underlying health conditions than the control group.

This TKM-based health promotion program presents a comprehensive and systemic health promotion strategy comprising medical examination and counselling, health education, daily management, and health monitoring. CCCs in Korea are usually small centers composed of a director and two or three childcare teachers and cannot have their own medical personnel and facilities. In this program, medical examinations and consultations by visiting TKM doctors can help determine children's current health and developmental levels. In addition, this program intended to increase children's health knowledge and interest in health through periodic health education and health monitoring using a self-reported health diary. To facilitate this multi-faceted program, not only visiting TKM doctors but also CCC teachers and caregivers were given cooperative roles. This is in line with the recent trend of emphasizing the partnership of diverse personnel in child health care [36].

Traditional and complementary and alternative medicine (T\&CAM) has been used to treat children's health problems in many Western countries. In the United States, the Integrative Therapies Team Program of Boston Children's Hospital has been established to provide massage therapy, guided imagery, reiki, acupuncture, expressive arts, and yoga [37]. This Team program is also available in Minnesota, Philadelphia, Colombia, Utah, and Orange County [38-42]. In Germany, the Integrative Pediatrics project (Integrative Pädiatrie Projekt) was operated from 2015 to 2017 [43, 44], and the Integrative Pediatrics Center (Center de pédiatrie intégrative) of Switzerland has been providing homeopathic medicine, herbal medicine, acupuncture, and cupping for pediatric diseases since $2015[45,46]$. These cases have used T\&CAM on children's diseases in hospital settings, so few have investigated the effects of T\&CAM on health promotion in community settings, as in this study.

A potential limitation of this study is that TKM doctors were included according to their voluntary participation without restricting for their clinical careers or major medical fields. This was due to the fact that many childcare facilities in South Korea had difficulty securing medical professionals [47-49], and we not only wanted to secure a sufficient number of medical professionals in this study but also a realistic operational model that would be easier to introduce if the program is institutionalized in the future. To minimize variations caused by the difference in performance capabilities among TKM doctors, we prepared a program manual, standard consultation form, and educational materials and held a pre-workshop for TKM doctors. Another limitation was that the three months of intervention period was relatively short to determine the disease prevention effect through the health promotion program, and follow-up after the intervention period was not performed. Although it was possible to observe changes in some program outcomes despite these limitations, it is necessary to consider a longer period of intervention and follow-up observations when designing further studies.

\section{Conclusions}

This study identified health-related problems and environments of disadvantaged children in South Korea, developed a standard TKM-based health promotion program, and evaluated its effectiveness. We identified the positive possibility of a comprehensive health promotion program based on TKM in terms of the medical use and health conditions of disadvantaged children.

In the future, further consideration is necessary for the development of systems using TKM as part of various social approaches to improve the health of disadvantaged children. Prior to this, a long-term, successive, and large-scale follow-up study is needed for a systematic basis and objective evaluation.

\section{Abbreviations}

TKM: traditional Korean Medicine; CCC: Community Children's Center; DID: Difference-in-Differences; ZINB: zero-inflated negative binomial; IRR: Incident Rate Ratio; AIC: Akaike's Information Criterion; T\&CAM: Traditional \& Complementary and Alternative Medicine

\section{Declarations}

\section{Ethics approval and consent to participate}

This study was reviewed and approved by the Institutional Review Board (IRB) of Pusan National University Korean Medicine Hospital (IRB number PNUKHIRB-017: 2016005). Written informed consent was obtained from all children and their legal representatives (caregivers) before participating in the study. All procedures in the study were performed in accordance with the Declaration of Helsinki.

\section{Consent for publication}


Not applicable

\section{Availability of data and materials}

The datasets generated during the current study are available from the corresponding author on reasonable request.

\section{Competing interests}

The authors declare that they have no competing interests.

\section{Funding}

This study was supported by the Korean Ministry of Health and Welfare. The funding body had no role in the design of the study; data collection, analysis, and interpretation of data; or in writing the manuscript.

\section{Authors' contributions}

EH carried out the statistical analysis and drafted the manuscript. JR designed the study and collected data. KK and SL developed the intervention protocol and materials, and monitored the data collection. SK interpreted the data and revised the manuscript. BL designed the study and managed the whole process of study. All authors read and approved the final manuscript.

\section{Acknowledgements}

Not applicable

\section{References}

1. Marmot M, Friel S, Bell R, Houweling TAJ, Taylor S. Closing the gap in a generation: health equity through action on the social determinants of health. The lancet. 2008;372(9650):1661-9. https://doi.org/10.1016/S0140-6736(08)61690-6.

2. Goldfeld S, O'Connor M, Cloney D, Gray S, Redmond G, Badland H, et al. Understanding child disadvantage from a social determinants perspective. J Epidemiol Community Health. 2018;72(3):223-9. http://doi.org/10.1136/jech-2017-209036.

3. Case A, Fertig A, Paxson C. The lasting impact of childhood health and circumstance. Journal of Health Economics. 2005;24(2):365-89. http://doi.org/10.1016/j.jhealeco.2004.09.008

4. Pearce A, Dundas R, Whitehead M, Taylor-Robinson D. Pathways to inequalities in child health. Archives of Disease in Childhood. 2019;104(10):998-1003. http://doi.org/10.1136/archdischild-2018-314808.

5. Hoghughi M. The importance of parenting in child health: doctors as well as the government should do more to support parents. BMJ. 1998;316(7144):1545-50. http://doi.org/10.1136/bmj.316.7144.1545.

6. Park HL, Lee HS, Shin BC, Liu JP, Shang Q, Yamashita H, et al. Traditional medicine in China, Korea, and Japan: a brief Introduction and comparison. Evid Based Complement Alternat Med. 2012;429103. https://doi.org/10.1155/2012/429103.

7. Kim KH, Choi J, Go HY, Lee JA, Lee MS, Park S, et al. Health Promotion Programme using Traditional Korean Medicine (HaPP-TKM): An overview. European Journal of Integrative Medicine. 2015;7(6):628-33. http://doi.org/10.1016/j.eujim.2015.09.001.

8. Ministry of Health and Welfare, Korea Health Promotion Institution. Integrated community health promotion program 2020 - traditional Korean Medicine. South Korea: Division of traditional Korean Medicine policy; 2019 [Korean]. https://www.korea.kr/archive/expDocView.do? docld=38893.

9. Choi KJ, Kim HJ, Ahn SW. A research on the improvement measures about community-based Korean medical public health service in public service center. Korea Journal of Oriental Medicine. 2004;10(1):107-17 [Korean with abstract in English].

10. Park ES, Moon YH, Kim YH, Choi KH, Jang DW. A study for management and effects of children's care program with traditional korean medicine in public health center. J Korean Oriental Med. 2012;33(1):52-67 [Korean with abstract in English].

11. Byun EK, Chang KO. The effects of oriental medicine qi gong program on the anxiety and self efficacy among children using community child center. Journal of the Korea Academia-Industrial cooperation Society. 2014;15(3):1623-31 [Korean with abstract in English]. https://doi.org/10.5762/KAIS.2014.15.3.1623.

12. Chang DM. Current status and policy recommendations of oriental public health programs. Journal of Society of Preventive Korean Medicine. 2007;11(2):101-12 [Korean with abstract in English].

13. Lee EK, Chong MS, Lee KN. Considerations on a support system for oriental medicine public health programs. Journal of Society of Preventive Korean Medicine. 2011;15(3):1-16 [Korean with abstract in English].

14. Lee JS, Lee EK, Lee KN, Chong MS. Recognition of traditional korean medical public health program in public health oriental medical doctors. Journal of Society of Preventive Korean Medicine. 2011;15(2):115-30 [Korean with abstract in English].

15. Child Welfare Act. Article 52, paragraph 1, subparagraph 8. South Korea. 
16. Public data portal [dataset on the Internet]. The current status of community children center (2020). South Korea: Ministry of Health and Welfare. https://www.data.go.kr/data/15004404/fileData.do. Accessed 10 June 2021.

17. National Youth Policy Institute. A panel survey on children\&youths in socially disadvantaged families and welfare facilities III: focusing on the community child centers, after-school-academies and residential care facilities. South Korea: The Office for Government Policy Coordination; 2012 [Korean]. https://doi.org/10.23000/TRK0201300014929.

18. Ministry of Health. A guide to developing health promotion programmes in primary health care settings. New Zealand: Public Health Directorate; 2003.

19. Lee HL, Han JK, Kim YH. A study on comparison between growth Indices of weak children groups via analyzing bone age and body composition. The journal of pediatrics of Korean medicine. 2014;28(2):1-22[Korean with abstract in English]. https://doi.org/10.7778/jpkm.2014.28.2.001.

20. Koh H. Functional abdominal pain in children. Korean J Pediatr Gastroenterol Nutr. 2011;14(2):222-31. http://doi.org/10.5223/kjpgn.2011.14.3.222.

21. Jang BS. The Effects of meridian acupressure on abdominal pain in children of school year [dissertation]. Busan, South Korea: Busan national university of education; 2013.

22. Korean Statistical Information Service [dataset on the Internet]. Current status of National Health Insurance by disease classifications and age (total, 2014). South Korea: National Health Insurance Corporation, Health Insurance Review and Assessment Service. https://stat.kosis.kr/statHtml_host/statHtml.do?orgld=350\&tblld=TX_35001_A061\&dbUser=NSI_IN_350. Accessed 21 Mar 2021.

23. Park M, Park J, Kwon S. Effect of a comprehensive health care program by korean medicine doctors on medical care utilization for common Infectious diseases in child-care centers. Evid Based Complement Alternat Med. 2014;2014:781675. https://doi.org/10.1155/2014/781675.

24. Braveman P, Egerter S, Williams DR. The social determinants of health: coming of age. Annu Rev Public Health. 2011;32(1):381-98. http://doi.org/10.1146/annurev-publhealth-031210-101218.

25. Korea Institute for Health and Social Affairs. Current status of child. South Korea: Ministry of Health and Welfare; 2018 [Korean]. https://www.korea.kr/archive/expDocView.do?docld=38696.

26. Son M, Kim J, Oh J, Kawachi I. Inequalities in childhood cancer mortality according to parental socioeconomic position: A birth cohort study in South Korea. Soc Sci Med. 2010;72(1):108-15. http://doi.org/10.1016/j.socscimed.2010.10.007.

27. Dong Y, Peng CYJ. Principled missing data methods for researchers. Springer Plus. 2013;2(1):222. https://doi.org/10.1186/2193-1801-2-222.

28. Newll DJ. Intention-To-Treat analysis: implications for quantitative and qualitative research. Int J Epidemiol. 1992;21(5):837-41. https://doi.org/10.1093/ije/21.5.837.

29. Lechner M. The estimation of causal effects by difference-in-difference methods estimation of spatial panels. Foundations and Trends $\AA^{\circ}$ in Econometrics. 2011;4:165-224. http://doi.org/10.1561/0800000014.

30. Lambert D. Zero-inflated poisson regression, with an application to defects in manufacturing. Technometrics. 1992;34(1):1-14. https://doi.org/10.2307/1269547.

31. Ridout M, Demétrio CGB, Hinde J. Models for count data with many zeros. Proceedings of the XIX International Biometric Conference. 1998;19:179-92.

32. King G. Unifying political methodology: The likelihood theory of statistical inference. England: Cambridge University Press; 1989. https://doi.org/10.3998/mpub.23784.

33. Vuong QH. Likelihood ratio tests for model selection and non-nested hypotheses. Econometrica. 1989; 57(2): 307-33. https://doi.org/10.2307/1912557.

34. Akaike H. Information theory and an extension of the maximum likelihood principle. Parzen E, Tanabe K, Kitagawa G, editors. New York: Springer; 1998. https://doi.org/10.1007/978-1-4612-1694-0_15.

35. Wilson P. The misuse of the Vuong test for non-nested models to test for zero-inflation. Economics Letters. 2015;127:51-3. https://doi.org/10.1016/j.econlet.2014.12.029.

36. Inkelas M, Oberklaid F. Improving preventive and health promotion care for children. Israel Journal of Health Policy Research. $2018 ; 7: 62$. https://doi.org/10.1186/s13584-018-0259-3.

37. Boston Children's Hospital [Internet]. Integrative Therapies Team Program; c2020. https://www.childrenshospital.org/centers-andservices/programs/f-_-n/integrative-therapies-team-program\#. Accessed 26 Dec 2020.

38. Children's Minnesota [Internet]. Integrative medicine - A team that treats the body, mind and spirit. https://www.childrensmn.org/services/carespecialties-departments/integrative-medicine/meet-the-team. Accessed 5 Jan 2021.

39. The Children's Hospital of Philadelphia [Internet]. About the integrative health program. https://www.chop.edu/centers-programs/integrativehealth/about. Accessed 5 Jan 2021.

40. Columbia university department of pediatrics [Internet]. Integrative therapies. https://www.pediatrics.columbia.edu/aboutus/divisions/hematology-oncology-and-stem-cell-transplantation/center-comprehensive-wellness/patient-care/integrative-therapies. Accessed 7 Jan 2021. 
41. Intermountain primary children's hospital [Internet]. Integrative medicine. https://intermountainhealthcare.org/primary-childrens/programsspecialties/integrative-medicine. Accessed 10 Jan 2021.

42. Children's Health Orange County [Internet]. Integrative Health. https://www.choc.org/programs-services/integrative-health. Accessed 10 Jan 2021.

43. Karl und Veronica Carstens-Stiftung [Internet]. Integrative Pädiatrie - Naturheilkunde und Homöopathie in der Kinder- und Jugendmedizin; 2017. https://www.carstens-stiftung.de/paediatrie.html. Accessed 26 Dec 2020.

44. Eckert M, Amarell C, Anheyer D, Cramer H, Dobos G. Integrative pediatrics: successful implementation of integrative medicine in a german hospital setting-concept and realization. Children. 2018; 5(9):122. https://doi.org/10.3390/children5090122.

45. Pädiatrie schweiz [Internet]. Integrative Pädiatrie am HFR Freiburg - Kantonsspital. https://www.paediatrieschweiz.ch/integrative-padiatrie-amhfr-freiburg-kantonsspital. Accessed 10 Feb 2021.

46. HFR hôpital fribourgeois [Internet]. Centre de pédiatrie intégrative. https://www.h-fr.ch/nos-specialites/nos-centres-de-competences/centre-depediatrie-integrative. Accessed 10 Feb 2021.

47. Kim SJ, Lee JE, Yang SO, Kang KA, Chang EY, Oh KS, et al. Perception of child day care center teachers on issues and needs in child health management. Journal of Korean academy of child health nursing. 2011;17(1):10-21 [Korean with abstract in English]. https://doi.org/10.4094/jkachn.2011.17.1.10.

48. Choo JA, Kim HJ, Yang HM, KIM SY. An obesity prevention framework for vulnerable children based on a methodology of community-based participatory research: using a strategy of training community lay health advisors. Korea: Ministry of Health and Welfare, Korea Health Promotion Foundation; 2013 [Korean].

49. Park ES, Im YJ, Cho EJ. Development of an ecological model to improve health care management for children in child care centers. Child Health Nursing Research. 2013;19(1):59-68 [Korean with abstract in English]. https://doi.org/10.5468/CHNR.2013.19.1.59.

\section{Figures}

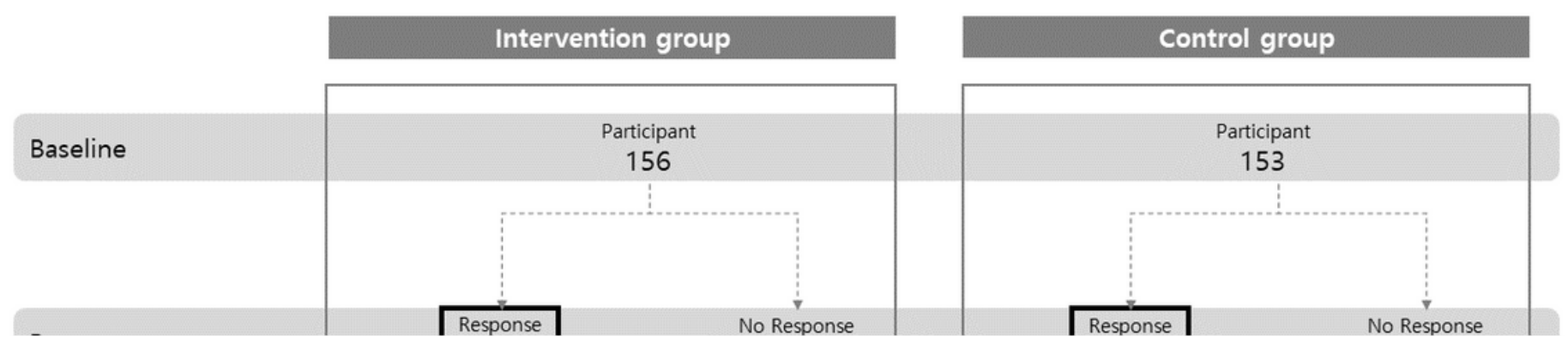

\section{Figure 1}

The result of participation and data collection 